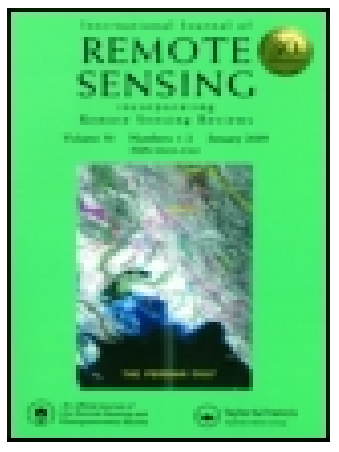

International Journal of Remote Sensing

ISSN: 0143-1161 (Print) 1366-5901 (Online) Journal homepage: http://www.tandfonline.com/loi/tres20

\title{
On the analysis of a time series of $X$-band TerraSAR-X SAR imagery over oil seepages
}

\section{F. Nunziata, C. R. de Macedo, A. Buono, D. Velotto \& M. Migliaccio}

To cite this article: F. Nunziata, C. R. de Macedo, A. Buono, D. Velotto \& M. Migliaccio (2018): On the analysis of a time series of X-band TerraSAR-X SAR imagery over oil seepages, International Journal of Remote Sensing, DOI: 10.1080/01431161.2018.1547933

To link to this article: https://doi.org/10.1080/01431161.2018.1547933

\section{Published online: 20 Nov 2018.}

Submit your article to this journal

山 Article views: 22

View Crossmark data ¿ 


\title{
On the analysis of a time series of X-band TerraSAR-X SAR imagery over oil seepages
}

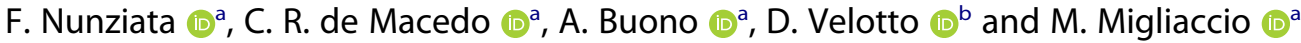

aDipartimento di Ingegneria, Università degli Studi di Napoli Parthenope, Napoli, Italy; ${ }^{\text {b} R e m o t e ~ S e n s i n g ~}$ Technology Institute, German Aerospace Center (DLR), Bremen, Germany

\begin{abstract}
A large time series of 42 dual-polarimetric co-polarized TerraSARX (TSX) StripMap Synthetic Aperture Radar (SAR) measurements are exploited to monitor a well-known oil seep area, i.e., the Taylor Energy site in the Gulf of Mexico. A comprehensive scattering analysis is undertaken to assess the impact of SAR imaging parameters (polarization, angle of incidence - AOI, noise floor) and environmental conditions (wind speed - WS, oil properties) on single-polarization SAR-based sea oil seep observation. The main goal of this study is to evaluate the reliability of the scatteringbased information derived from the time series of TSX SAR imagery. A two-scale backscattering model is considered to give a physical framework that supports a better understanding of the effects of the above-mentioned factors.

Experimental results showed that the high TSX noise floor significantly limits a reliable interpretation of the slick-free sea surface and oil seep backscattering at AOIs larger than $34^{\circ}$ and $26^{\circ}$, respectively, since they are contaminated by noise. Hence, it is shown that, at larger AOls, the joint contribution of noisy SAR measurements and low oil backscattering does not result in a larger oil/sea separability. The latter is not remarkably influenced by polarization and WS, under low-to-moderate conditions. Experiments also demonstrate that, when reliable SAR measurements are available, sea oil seep backscattering is affected by the oil's damping properties more than its concentration in the water column. The time variability of the polluted area is also estimated using the time series of TSX imagery and the obtained results agree with independent analysis undertaken on the same test site.
\end{abstract}

\section{ARTICLE HISTORY}

Received 17 May 2018

Accepted 27 October 2018

\section{Introduction}

Oil seepages include natural flow of gaseous and liquid hydrocarbons drifting from below the sediments through the water column, as well as loss from leaking reservoirs (Woods 2011). Naturally occurring oil seepages from the seafloor are the largest source of oil entering the world ocean (they account for nearly half of the oil released into the ocean environment every year) and, as well as deliberated/accidental oil discharges, they

CONTACT F. Nunziata ferdinando.nunziata@uniparthenope.it $\Theta$ Dipartimento di Ingegneria, Università degli Studi di Napoli Parthenope, Centro Direzionale isola C4, Napoli 80143, Italy 
can be toxic to marine mammals, seabird, fish, and benthic communities and they also pose threats to the human health (Gesteira and Dauvin 2000; NRC 2003).

Observing oil seepages is of paramount importance to protect the environment and in the context of oil exploration activities. The latter are nowadays moving onto the deep and ultra deep ocean waters; hence, resulting in progressively higher risk and costly exploration activities.

Therefore, offshore oil seepages observation by high-resolution spaceborne remote sensing instruments acts as a marker of the presence of hydrocarbons, thus offering an effective and cheaper way to locate offshore oil reserves (Jatiault et al. 2017). Spaceborne Synthetic Aperture Radar (SAR), due to its all-weather fine spatial resolution imaging capabilities, is a powerful tool to observe anthropogenic sea oil slicks. In simple terms, the underpinning simplified physical rationale relies on the fact that oil slicks, reducing the short Bragg resonant waves, generate low backscatter areas which, in the SAR image plane, appear as patches darker than the background sea (Wismann et al. 1998; Nunziata, Sobieski, and Migliaccio 2009). However, the phenomenology of oil seeps is completely different from conventional oil spills. In fact, while conventional oil spills usually appear as thin (e.g., $1 \mu \mathrm{m}$ to $1 \mathrm{~mm}$ ) surfactants floating over the ocean (Leifer et al. 2012; Fingas 2018), oil seeps manifest themselves as crude oil droplets, different in size, shape, and distribution, flowing in a non-uniform way from the bottom of the ocean upward towards the surface (Woods 2003). The subsurface evolution of oil seeps is mainly driven by underwater horizontal currents, vertical turbulence and buoyancy of oil droplets, and other water mass movements that steer the trajectory of oil droplets into the water column, while the surface fate of oil seeps is ruled by ocean surface currents, winds and other meteo-marine conditions that determine shape and lifespan of the slick (Valentine et al. 2014).

Operational SAR-based sea oil slick observation mainly relies on single-polarization SAR imagery that allow observing very large areas with a moderate-to-fine spatial resolution (Brekke and Solberg 2005; Gade et al. 1998; Wismann et al. 1998; Mera et al. 2017; Solberg 2012; Cheng et al. 2014). Methods developed in literature mainly consist of computer-based approaches, i.e., neural networks, support vector machine, etc., aimed at detecting surface oil spills against the sea surface background and discriminating them from oil look-alikes. This task is accomplished extracting from single-polarization SAR imagery a large set of features, including intensity and morphological parameters of the selected dark area, which provide a certain probability that the detected dark area is due to an oil slick (Brekke and Solberg 2005; Gambardella et al. 2010). Nevertheless, although several studies aimed at exploiting large time series of single-polarization SAR imagery for sea oil spill detection have been proposed (Mera et al. 2017; Garcia-Pineda et al. 2017; Solberg, Brekke, and Husoy 2007; Del Frate et al. 2000; Solberg et al. 1999; Girard-Ardhuin et al. 2005; Xu et al. 2016; Singha, Bellerby, and Trieschmann 2013), fewer studies dealt with the monitoring of sea oil seeps even if, in recent years, they are receiving greater attention due to the exploration of deep and ultra-deep waters (Jatiault et al. 2017; Suresh et al. 2015; de Miranda et al. 2004; GarciaPineda et al. 2009; Korber et al. 2014).

When dealing with sea oil slick observation, several methodologies have been proposed that are typically tested using large data set of SAR imagery (i.e., from about 20 up to about 2000 scenes) collected over different areas (Mediterranean basin, Baltic and 
North Sea, Spanish and Canadian Atlantic coasts and Gulf of Mexico), at different incident wavelengths ( $\mathrm{L}-, \mathrm{C}-$ and, $\mathrm{X}$-band) and in an extremely wide range of angle of incidence - AOI $\left(15^{\circ}-60^{\circ}\right)$. When dealing with natural oil seeps studies, time series of single-polarization SAR imagery are typically exploited. For instance, in (de Miranda et al. 2004; Garcia-Pineda et al. 2009) and (Suresh et al. 2015; Korber et al. 2014) time series of about 12 up to about 700 C-band SAR scenes acquired over well-known oil seeps in the Gulf of Mexico (Cantarell, Campeche Bay) and Black Sea (Colkethi, Pechori Mound, Batumi and Kobuleti Ridge), respectively, are exploited. In (Jatiault et al. 2017), a large time series of $\mathrm{C}$ - and $\mathrm{X}$-band SAR images collected over the same study area, i.e., the lower Congo basin, is considered.

All those studies aim at detecting oil seepages generated by the migration from the seabed faults, distinguishing them from other similar oil slick signatures due to ship/ tankers oil spills or oil look-alikes due to biogenic slicks or other marine-induced phenomena, identifying the location of the oil seep sites, providing a rough estimation of the amount of leaked oil and tracking the time evolution of the oil seep. A deeper analysis of the state-of-the-art related to oil seeps monitoring witnesses that:

- Sea oil seep monitoring is a quite different task if compared to conventional sea oil slick observation due to the irregular nature of oil seepages, which is due to random factors as flow rate, surface and subsurface meteo-marine conditions and oil's fate;

- SAR represents an important source of information. However, due to the influence of geological seafloor and oceanographic surface context on sea oil seeps monitoring, a multi-disciplinary approach is strongly suggested to help a complete understanding of the phenomenon;

- SAR-based sea oil seeps monitoring is largely based on the exploitation of consistent and homogeneous time series of SAR imagery that inherently carry on a larger amount of information with respect to the single SAR scene.

In practical cases, those time series were constructed considering SAR scenes collected over the same area by different SAR sensors and at different AOls, polarization, imaging modes, and environmental conditions (Garcia-Pineda et al. 2017; Singha, Bellerby, and Trieschmann 2013; Solberg, Brekke, and Husoy 2007; Jatiault et al. 2017; Suresh et al. 2015). This poses a key question related to the reliability of the scattering-based features that depend on both SAR acquisition parameters (AOI, wavelength, polarization, and Noise Equivalent Sigma Zero - NESZ), environmental conditions (wind speed - WS) and oil properties (damping, volume fraction). Accordingly, it is of paramount importance investigating backscattering from oil-covered sea surface at varying SAR and environmental parameters. Although the effects of incident wavelength, AOI, polarization, NESZ, WS, and oil properties on sea oil slick detection have been investigated in several studies (Gade et al. 1998; Wismann et al. 1998; Minchew, Jones, and Holt 2012; Brekke et al. 2014; Skrunes, Brekke, and Eltoft 2014, Skrunes et al. 2016; Buono et al. 2016; Skrunes et al. 2015; Brekke et al. 2016; Ivonin et al. 2016; Latini, Del Frate, and Jones 2016; Nunziata, Buono, and Migliaccio 2018), such experiments exploited only a limited number of SAR images that were typically collected by different SAR sensors and/or in different locations, with a narrow range of AOls and limited sea state conditions. 
To the best of our knowledge, there is no comprehensive study aimed at:

- Addressing the backscattering from sea oil seeps exploiting a large and homogeneous time series of $X$-band TerraSAR-X (TSX) SAR imagery;

- Discussing the reliability of the scattering-based information extracted from a time series of TSX SAR imagery collected over a well-known test site with respect to SAR and environmental parameters.

Hence, in this study, a time series of dual-polarimetric SAR measurements, collected by the German X-band TSX mission, is exploited to observe the well-known oil seepage related to the Taylor Energy oil platform site in the Gulf of Mexico. The time series consists of 42 TSX StripMap imagery collected over the same test site with different polarization (horizontal transmit and receiving, $\mathrm{HH}$, and vertical transmit and receiving, VV), AOI, and meteo-marine conditions. In particular, the analysis addresses to what extent single-polarization SAR oil slick observation is affected by the above-mentioned factors and by NESZ, pointing out the effects of SAR acquisition parameters and environmental conditions on $\mathrm{VV}-$ and $\mathrm{HH}-$ polarized backscattering from slick-free and oiled area in order to give an understanding of their joint effects on oil/sea separability and, therefore, on the actual benefits of the time series for sea oil seepages observation. To provide a physical background that helps in better understanding the role of the above-mentioned parameters, a scattering model based on the two scale boundary perturbation backscattering model (BPM) is adopted to predict slick-free and oil-covered backscattering. The latter is addressed analysing both the surface and the electric effects of the oil slick.

Model predictions and experimental results show that:

- The time series of TSX imagery is significantly affected by NESZ. This means that a reliable interpretation of oil backscattering can be only undertaken at lower AOI. At larger AOI, i.e., $>$ about $26^{\circ}$, the signal arising from the oil slick is significantly corrupted by noise;

- Slick-free backscattering is also affected by NESZ. This implies that at incidence angles larger than about $34^{\circ}$ the signal scattered-off slick-free sea surface is corrupted by noise;

- The two co-polarized channels provide similar performance in terms of oil/sea separability showing that the influence of WS, under low-to-moderate conditions, is almost negligible;

- When lower AOls are considered, backscattering from oil seep is mainly affected by the damping properties of the surfactant. This implies that oil concentration in the water column, in real cases, plays a marginal role.

In addition, the time variability of the polluted area is also estimated using the time series of TSX imagery according to the co-polarized phase difference (CPD) approach proposed in (Migliaccio, Nunziata, and Gambardella 2009; Velotto et al. 2011).

\section{Study area and time series of SAR imagery}

The study area (Figure 1) is located in the northern part of the Gulf of Mexico near the Mississippi River delta and extends between $28^{\circ} 30^{\prime} 00^{\prime \prime} \mathrm{N}-29^{\circ} 30^{\prime} 00^{\prime \prime} \mathrm{N}$ and $88^{\circ} 0^{\prime} 00^{\prime \prime} \mathrm{W}-$ 


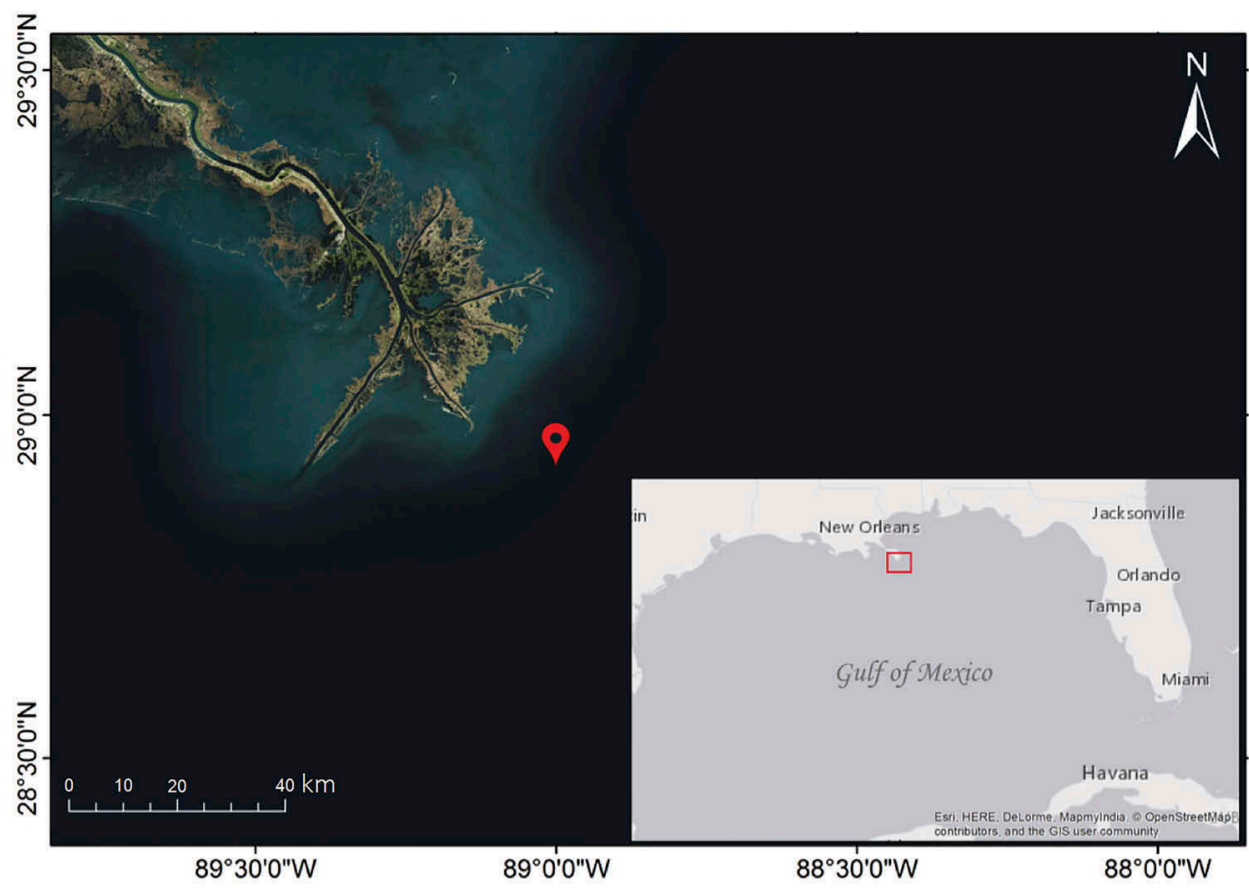

Figure 1. Map of the study area, which is located in the northern part of the Gulf of Mexico, close to the Mississippi river delta. The location of the Taylor Energy oil drilling platform is marked in red.

$89^{\circ} 30^{\prime} 00^{\prime \prime} \mathrm{W}$. This area is extremely rich in oil seepages (Migliaccio et al. 2012; Minchew 2012; Migliaccio and Nunziata 2014; Garcia-Pineda et al. 2017). We focused on the area where the Taylor Energy oil drilling platform is located $\left(28^{\circ} 56^{\prime} 17^{\prime \prime} \mathrm{N}, 88^{\circ} 58^{\prime} 16^{\prime \prime} \mathrm{W}\right)$, see the red marker in Figure 1. The platform was destroyed by the Hurricane Ivan in 2004 and, since then, the underwater wells were continuously leaking oil from approximately $150 \mathrm{~m}$ depth (Gulf Monitoring Consortium 2011). It was estimated that more than 100 oil gallons enter into the marine environment from the Taylor Energy platform site. This results in surface oil slicks whose average thickness and lifetime are about $1 \mu \mathrm{m}$ and 4 days, respectively (Gulf Monitoring Consortium 2011).

In order to monitor this area, dual-polarimetric HH-VV TSX SAR imagery have been acquired in StripMap mode, see Figure 2. The area was observed to be persistently affected by this anthropogenic oil seep as the slicks were detected in almost $80 \%$ of the data collected over the site (Gulf Monitoring Consortium 2011). Even if strictly speaking this leakage cannot be considered as a natural oil seep, the underwater origin of the oil seep together with the involved weathering and ageing processes are fairly the same. Hence, it represents a good opportunity to have a large and consistent time series of SAR imagery that covers a well-known oil seepage.

A time series of 42 dual-polarimetric HH-VV TSX SAR imagery, collected in StripMap mode between July 2011 and April 2016, is exploited. The time series is partitioned into 3 subsets, each consisting of 14 SAR scenes, according to the average AOI (i.e., $26^{\circ}, 34^{\circ}$, and $43^{\circ}$ ), see Table 1.

WS information provided by scatterometer measurements and buoy data (buoy 'Pill1' $\left(29^{\circ} 10^{\prime} 44^{\prime \prime} \mathrm{N}, 89^{\circ} 15^{\prime} 32^{\prime \prime} \mathrm{W}\right)$ and ' $42,040^{\prime}\left(29^{\circ} 12^{\prime} 29^{\prime \prime} \mathrm{N}, 88^{\circ} 13^{\prime} 34^{\prime \prime} \mathrm{W}\right)$, which are about $70 \mathrm{~km}$ far 
(a)

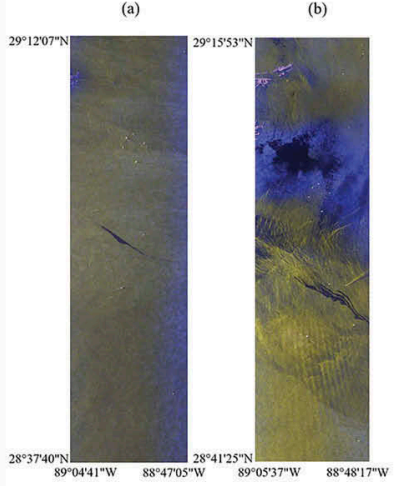

(c)

(d)

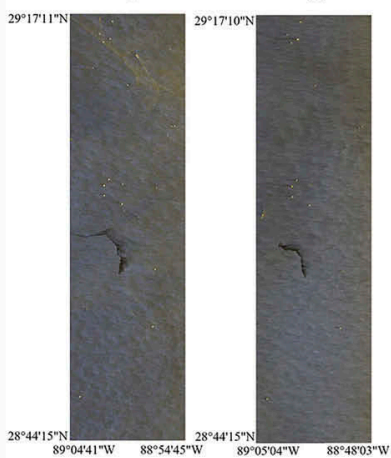

(c)

(f)

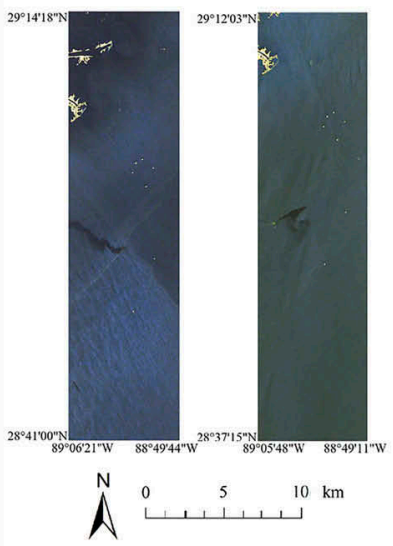

Figure 2. TSX ScanSAR imagery. False colour Pauli images excerpted from the whole dataset collected over the study are at: (a)-(b) $26^{\circ}$, (c)-(d) $34^{\circ}$, (e)-(f) $43^{\circ}$. The oil seep signature that changes over time in size and shape is visible as a patch darker than the surrounding sea.

from the platform site) is also available, see (Remote Sensing System 2017; NOAA 2017). All SAR imagery were acquired under low-to-moderate WS, ranging from 1.8 to $8.4 \mathrm{~m} \mathrm{~s}^{-1}$.

Figure 3 shows three dual-polarimetric SAR scenes collected over the same area at different AOls. Note that the image is arranged in matrix format with the two columns stand for $\mathrm{HH}-$ and V-polarized normalized radar cross section (NRCS) imagery, while the three rows refer to 
Table 1. General information on the time series of SAR imagery. Please note that NESZ values refer to the $\mathrm{HH}$ channel.

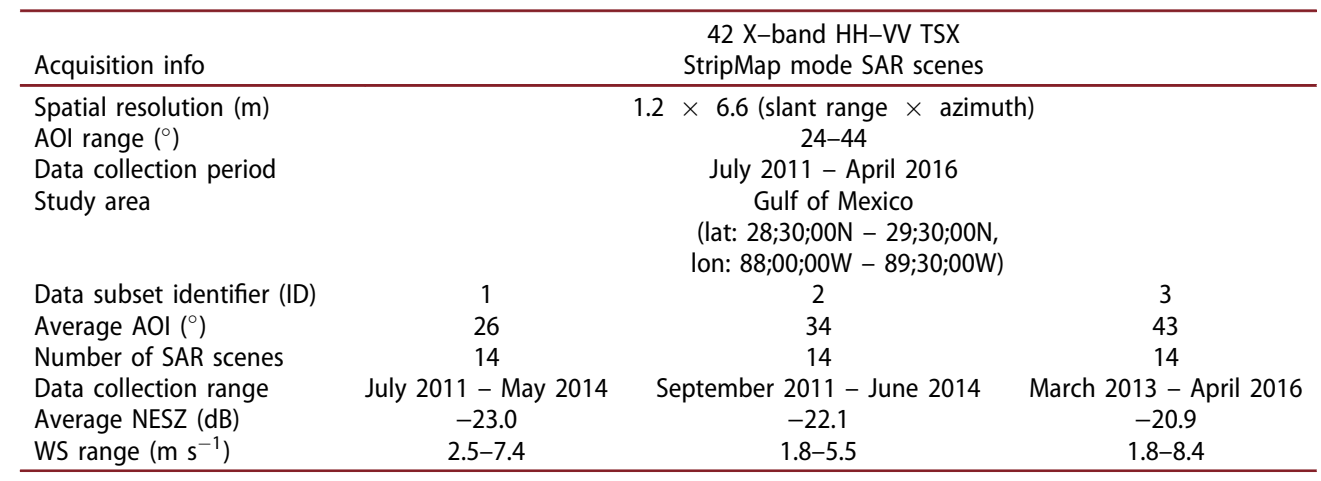

$26^{\circ}, 34^{\circ}$ and $43^{\circ} \mathrm{AOI}$, respectively. Surface signatures related to the oil seep are visible as patches darker than the sea background even if, although the same oil seep is imaged in all the SAR scenes, due to the spatial/temporal variability of the oil seep and the different acquisition geometry, the oil slick area changes from one image to another.

\section{Backscattering model}

The lower backscattered signal due to a sea oil slick is typically explained by the damping properties of anthropogenic oil slicks that reduce the small Bragg resonant waves. Hence, oil-covered sea surface results in a smaller percentage of the radar signal to be scattered back to the radar antenna. This physical rationale is based on the fact that, when anthropogenic oil usually exists as very thin surface slicks that are much thinner ( $\approx \mu \mathrm{m})$ than the radar incident wavelength (in the range of few centimetres) Fingas (2018). As a result, the different electromagnetic properties that characterize oil and water have a negligible effect on the backscattered signal. This is no longer true when dealing with oil-in-water emulsions or thicker oil layers due to weathering processes (Alpers, Holt, and Zeng 2017).

When dealing with oil seeps, since oil comes from the bottom of the sea, a completely different scenario applies since the whole water column is affected by oil. This implies that the layer that interacts with the incident wave (which at X-band extends up to few centimetres below sea surface (Skrunes et al. 2015)) consists of an oil/water mixture (Minchew, Jones, and Holt 2012; Minchew 2012). Accordingly, to predict the signal scattered off the oil/water layer, three effects must be accounted for (see Figure 4):

- The damping of the wind-driven surface roughness;

- The reduction of the wind input to the sea waves;

- The effective permittivity of the oil/water layer.

Hence, in such a case, the scattering model must take into account the effects of both oil's damping and oil/water mixture permittivity.

Before characterizing the signal backscattered off an oil seep, it is worth discussing slickfree sea surface backscattering. In this study, Bragg scattering theory, augmented by a twoscale sea surface model to account for long-wave structure, is adopted (Voronovich 1985). 
(a)
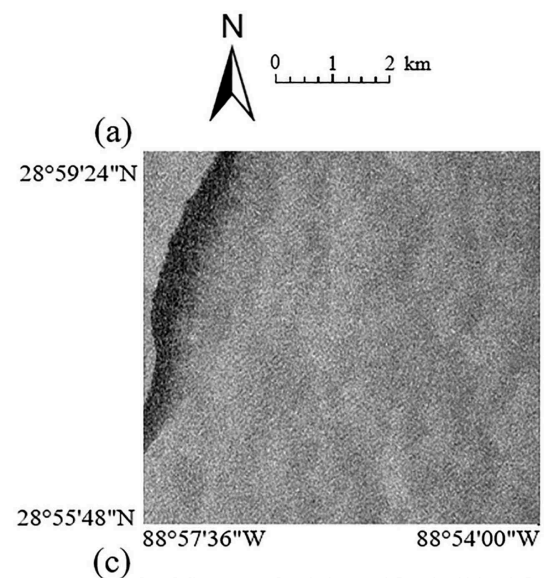

$180^{\circ}$

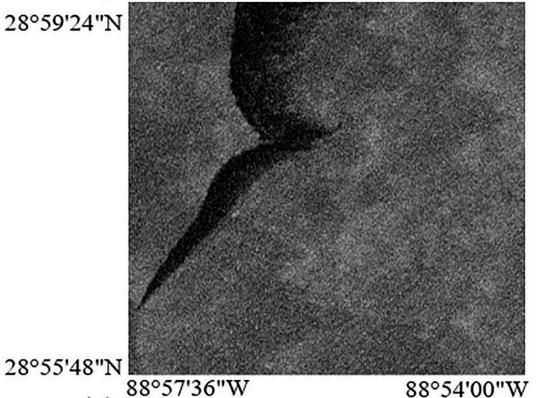

(e)

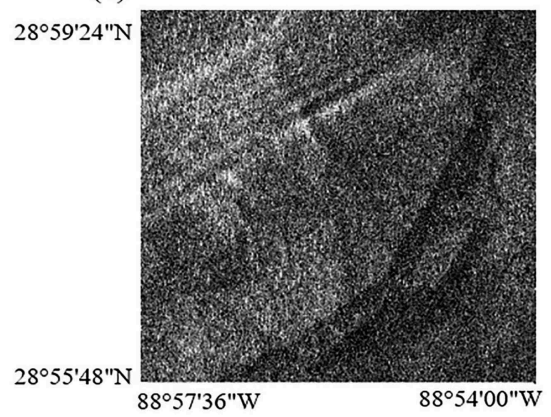

(b)

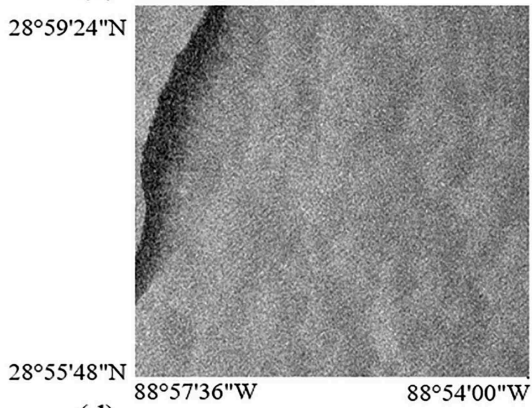

(d)

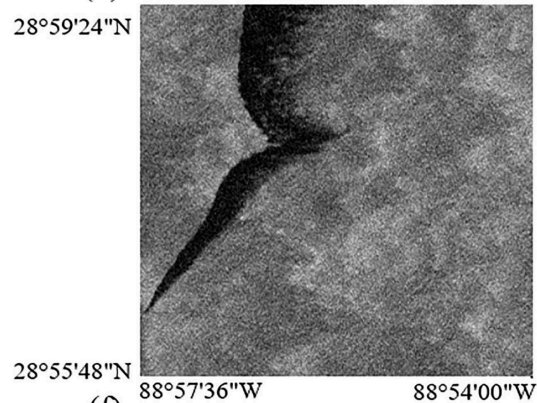

(f)

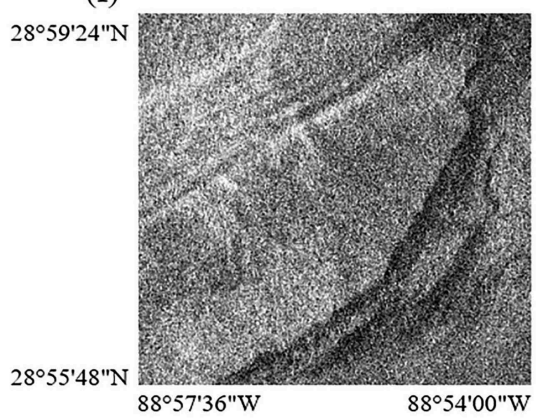

$\sigma_{\mathrm{VV}}^{0}(\mathrm{~dB})$

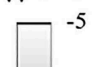

$-10$

$-15$

$-20$

Figure 3. Excerpts of NRCS images relevant to three SAR scenes randomly selected from each AOI-based subset of the time-series (see Table 1): rows (columns) refer to different AOls (polarizations). (a)-(b) represent $\mathrm{HH}-$ and $\mathrm{VV}$-polarized images, respectively, relevant to the SAR scene imaged on 28 October 2013 with $\mathrm{AOI}=26^{\circ}$; (c)-(d) represent $\mathrm{HH}$ - and VV-polarized images, respectively, relevant to the SAR scene imaged on 27 October 20272013 with AOI = 34 $4^{\circ}$ (e)-(f) represent HH- and VVpolarized images, respectively, relevant to the SAR scene imaged on 11 April 2016 with $\mathrm{AOI}=43^{\circ}$.

Hence, over an AOI range that spans approximately from $20^{\circ}$ up to $60^{\circ}$ and under low-tomoderate wind conditions, sea surface backscattering is given, according to (Guissard, Sobieski, and Baufays 1992; Boukabara et al. 2002), by Equation (1): 


\section{INPUTS}

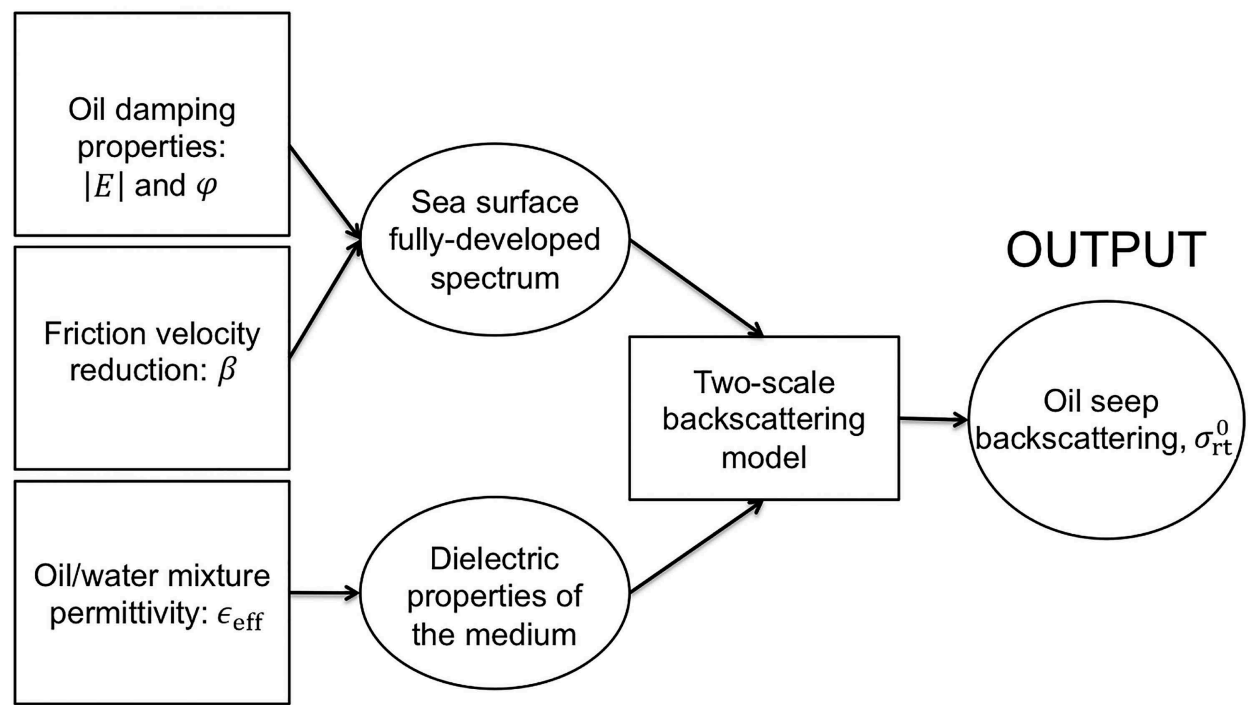

Figure 4. Sketch of NRCS model for the oil seep backscattering.

$$
\begin{aligned}
\sigma_{\mathrm{rt}}^{0}= & \frac{\pi}{\cos ^{2} \tau_{\mathrm{sp}}}\left|R_{\mathrm{rt}, \mathrm{eff}}\left(\theta_{\mathrm{loc}}\right)\right|^{2} T_{\mathrm{sl}}\left(a_{\mathrm{sp}}, \beta_{\mathrm{sp}}\right) \\
& +\frac{k^{2}}{4 \pi\left(v_{\mathrm{z}} / k\right)^{2}} \iint\left|H_{\mathrm{rt}}\left(K_{\mathrm{x}}^{\prime}, K_{\mathrm{y}}^{\prime}\right)\right|^{2} \psi_{R}\left(K_{\mathrm{x}}, K_{\mathrm{y}}\right) T_{\mathrm{sl}}\left(K_{\mathrm{x}}^{\prime}, K_{\mathrm{y}}^{\prime}\right) d K_{\mathrm{x}} d K_{\mathrm{y}}
\end{aligned}
$$

where $\sigma_{\mathrm{rt}}^{0}$ stands for NRCS while $\mathrm{t}, \mathrm{r}$ indicate the transmitted and received polarization, respectively, $\tau_{\mathrm{sp}}$ is the angle between the local normal and the vertical, $R_{\mathrm{rt} \text {,eff }}$ is the effective Fresnel reflection coefficient that accounts for the reduction of the specular-like backscattering due to the small-scale roughness on the tangent plane, $\theta_{\text {loc }}$ is the local AOI, $T_{\mathrm{sl}}(\cdot)$ is the slope distribution evaluated at the specular points $\alpha_{\mathrm{sp}}$ and $\beta_{\mathrm{sp}}, k$ is the electromagnetic wavenumber, $H_{\mathrm{rt}}(\cdot)$ is the surface field function which depends on AOI and the dielectric constant of the medium $\epsilon_{\mathrm{W}}$, and $\psi_{\mathrm{R}}$ is the normalized ripple spectrum (Guissard, Sobieski, and Baufays 1992; Nunziata, Sobieski, and Migliaccio 2009). In Equation (1):

$$
K_{\mathrm{x}}^{\prime}=-\frac{v_{\mathrm{x}}-K_{\mathrm{x}}}{v_{\mathrm{z}}}, K_{\mathrm{y}}^{\prime}=-\frac{v_{\mathrm{y}}-K_{\mathrm{y}}}{v_{\mathrm{z}}},
$$

where $K_{\mathrm{x}}$ and $K_{\mathrm{y}}$ are the sea wavenumber components along the $\mathrm{x}$ and $\mathrm{y}$-axis, respectively, and where $v_{\mathrm{x}}, v_{\mathrm{y}}$ and $v_{\mathrm{z}}$ are the components along $\mathrm{x}, \mathrm{y}$, and $\mathrm{z}$-axis, respectively, of the vector

$$
\boldsymbol{v}=k(\mathbf{s}-\boldsymbol{i})
$$

which is the difference between the scattering $(\boldsymbol{s})$ and the incident (i) directions in terms of sea wavenumber. Equation (1), according to the two-scale model, predicts the backscattered signal (when $s=-i$ ) as the sum of two contributions. The first (leftmost-side of the second member) describes the signal backscattered off the long-wave part of the sea surface spectrum through the Geometric Optic (GO). The second (rightmost-side of 
the second member) accounts for the small-scale sea surface ripple, which is responsible for the untitled Bragg scattering, that is modulated by the large-scale roughness resulting in a tilted-Bragg scattering. This modulation is mathematically described by the convolution between $\psi_{\mathrm{R}}(\cdot)$ and the slope distribution $T_{\mathrm{sl}}(\cdot)$. Further details on the implementation of the numerical solution of Equation (1) are given in (Nunziata, Sobieski, and Migliaccio 2009) and references cited therein.

To predict sea surface backscattering, sea water permittivity, $\epsilon_{\mathrm{w}}$, is needed. The reference model is the Debye function that relates the dielectric properties of the sea water to the frequency $\omega$, the sea surface temperature and the salinity, SST, and SSS, respectively (Ellison et al. 1998; Meissner and Wentz 2004):

$$
\epsilon_{\mathrm{w}}(\omega, \mathrm{SST}, \mathrm{SSS})=\epsilon_{\mathrm{h}}+\frac{\epsilon_{\mathrm{S}}-\epsilon_{\mathrm{h}}}{1-\mathrm{j} \omega \tau}+\mathrm{j} \frac{\sigma}{\omega \epsilon_{0}},
$$

where $\epsilon_{\mathrm{s}}, \epsilon_{\mathrm{h}}$ and $\epsilon_{0}$ are the static, high frequency and vacuum dielectric constants, $\tau$ is the relaxation time, and $\sigma$ is the sea water conductivity. Note that $\epsilon_{s}, \epsilon_{h}, \tau$ and $\sigma$ depend on both SST and SSS. In (Ellison et al. 1998) an advanced model is proposed that allows predicting sea water permittivity with an error lower than $1 \%$ :

$$
\epsilon_{\mathrm{w}}=\epsilon_{\mathrm{h}}+\frac{\epsilon_{\mathrm{s}}-\epsilon_{\mathrm{h}}}{1+\omega^{2} \tau^{2}}+j\left(\frac{\left(\epsilon_{\mathrm{s}}-\epsilon_{\mathrm{h}}\right) \omega \tau}{1+\omega^{2} \tau^{2}}+\frac{\sigma}{\omega \epsilon_{0}}\right) .
$$

It must be pointed out that the high precision achieved by this model in predicting $\epsilon_{\mathrm{w}}$ is obtained for frequency (temperature) values lower (higher) than $40 \mathrm{GHz}\left(25^{\circ} \mathrm{C}\right)$ Ellison et al. (1998). To predict the signal backscattered off an oil seep, its geometric (i.e., damping and reduction of energy transfer) and dielectric effects must be considered. The damping effect can be approximated using the pure Marangoni viscous damping coefficient (Lombardini et al. 1989; Pinel, Déchamps, and Bourlier 2008, Pinel, Bourlier, and Sergievskaya 2014):

$$
C(K,|E|, \varphi)=\frac{1+X(\cos \varphi-\sin \varphi)+X Y-Y \sin \varphi}{1+2 X(\cos \varphi-\sin \varphi)+2 X^{2}},
$$

where $X$ and $Y$ are empirical coefficients that depend on the rheological parameters of the oil, i.e., its complex dilatational coefficient (modulus $|E|$ and phase $\varphi$ ), and on dynamic viscosity and density of the sea water.

The energy transfer from the wind to the sea waves is described by the friction velocity (Nunziata, Sobieski, and Migliaccio 2009; Montuori et al. 2016). Hence, the presence of a surfactant reduces the energy transfer to the waves and this phenomenon can be modelled by reducing the friction velocity through a penalty factor $\beta$ (Nunziata, Sobieski, and Migliaccio 2009; Montuori et al. 2016):

$$
u_{\mathrm{f}, \mathrm{o}}=\beta u_{\mathrm{f}} .
$$

where $u_{f}$ and $u_{f, o}$ are the friction velocities of the slick-free and slick-covered sea surface, respectively. The full-range sea surface spectrum related to the oiled sea surface can be obtained from the slick-free one using $u_{\mathrm{f}, \mathrm{o}}$ and $C(\cdot)$ :

$$
S_{o}\left(K, x, s, K_{\mathrm{o}},|E|, \varphi\right)=\frac{S\left(K, x, s, K_{\mathrm{o}}, u_{\mathrm{f}, \mathrm{o}}\right)}{C(K,|E|, \varphi)}
$$


where $x$ is the fetch, $s$ is the significant wave slope and $K_{o}$ is the peak wavenumber and $S(\cdot)$ is the slick-free sea surface spectrum. In this study, the full-range Elfouhaily sea surface spectrum is considered Elfouhaily et al. (1997). The latter is composed by an omnidirectional spectrum, decomposed into a low- and a high-frequency curvature spectrum to take into account the contributions of long gravity waves and short gravity-to-capillary waves, respectively, weighted by a spreading function which is symmetric with respect to wind direction. At low frequencies, the Elfouhaily sea surface spectrum is essentially an advanced version of the Pierson-Moskowitz spectrum, while high frequencies exhibit a cut-off due to viscosity damping out the smallest capillary waves.

When dealing with oil seeps, the above-described theoretical rationale must be specialized to describe their peculiarities (i.e., the oil affects the whole water column). Hence, the dielectric effect of the oil must be included. This can be described considering an oil/water mixture and deriving the effective dielectric constant. To describe the dielectric effects of the oil seep, an accurate model cannot be easily developed for a twofold reason: from the underwater side, the origin of an oil seep is strongly irregular, i.e., the oil leak rate and the droplets' features (concentration, distribution, size, and shape) are random. From the air-ocean interface side, the surface manifestation of an oil seep, i.e., the morphological complexity and the composition of the slick, changes with time as it is exposed to ageing and weathering processes (e. g., evaporation, emulsification, and dispersion) (Vilcaez, Li, and Hubbard 2013). Hence, two main assumptions are made to characterize the permittivity of the water column that hosts oil droplets:

- Oil droplets in the mixture are assumed to be homogeneous and spherical-shape;

- The radius of oil inclusions is smaller than the distance between each couple of them.

The first assumption states that oil droplets come from the same source and they present a spheroidal shape due to the upward flux driven by underwater currents and low-pressure conditions. The second hypothesis consists of neglecting multiple scattering effects when the oil concentration in the water column is small enough.

Hence, under these assumptions, the backattering of a heterogeneous oil/water mixture can be modelled as surface scattering from an equivalent medium characterized by an effective dielectric constant $\epsilon_{\text {eff }}$ (Skrunes et al. 2015 Brekke et al. (2014). The latter is modelled according to the Maxwell-Garnett approximation (Mallet, Guerin, and Sentenac 2005), where the oil/water mixture consists of randomly distributed spherical inclusions, i.e., oil droplets, with a given concentration, placed within a hosting medium, i.e., sea water (Shivola 1989):

$$
\epsilon_{\mathrm{eff}}=\epsilon_{\mathrm{w}} \frac{2\left(1-\delta_{i}\right) \epsilon_{\mathrm{w}}+\left(1+\delta_{i}\right) \epsilon_{\mathrm{o}}}{\left(2+\delta_{i}\right) \epsilon_{\mathrm{w}}+\left(1-\delta_{i}\right) \epsilon_{\mathrm{o}}}
$$

where $0 \leq \delta_{\mathrm{i}} \leq 1$ is the oil volume fraction within the water column, i.e., $\delta_{\mathrm{i}}=0$ (1) means slick-free (covered) sea surface, and $\epsilon_{\mathrm{o}}$ is the dielectric constant of the oil that depends on its chemical/physical properties, e.g., damping, viscosity, and density of its compounds. The latter change over time according to ageing and weathering phenomena. In (Friiso et al. 1998), it was found that such natural processes result in a slight reduction of the real part of $\epsilon_{0}$, while they have negligible effects on its imaginary part. 
Nevertheless, several studies pointed out that the real (imaginary) part of the crude oil permittivity belongs, at microwaves, to the range 2-3 (0.01-0.1) (Friiso et al. 1998).

This model represents a noise-free analysis of the slick-free and oiled backscattering. When contrasting model's predictions with actual SAR measurements noise must be accounted for since it limits the signal-to-noise ratio (SNR) to values below 3.0 decibels $(\mathrm{dB})$. The latter is typically considered a threshold to judge the reliability of the measurements (Skrunes, Brekke, and Eltoft 2014; Minchew, Jones, and Holt 2012; Brekke et al. 2016; Ivonin et al. 2016). Within this context, SAR observation of oil seeps (as well as sea oil slick observation) is a challenging application (Migliaccio, Nunziata, and Buono 2015; Alpers, Holt, and Zeng 2017). In fact, on one side, oil slicks generate low backscattering areas that result in a backscattering signal strength that is very close or even below the SAR instrument sensitivity, i.e., the NESZ. On the other side, SAR measurements are affected by additive noise. However, this noise source affects equally both slick-free and oil-covered backscattering (Migliaccio et al. 2009b). Hence, the main noise source that affects oil/sea separability is NESZ. The NESZ, which depends on a number of factors, e.g., the antenna pattern (i.e., the position in the scene), the power of the transmitted pulse, the quantization, the receiver noise, and the bandwidth, can be considered as a threshold to determine whether the received signal is reliable (its power is above NESZ) or not (its power is below NESZ). For TSX, the expected Noise Equivalent Beta Nought (NEBN) is annotated in the product's metadata file in form of polynomials over range at different azimuth time lags (Eineder et al. 2008). Each polynomial is used to get the image data noise power as a function of range considering that NESZ and NEBN are directly related by the AOI, which for sea surface is given directly by the acquisition geometry.

\section{Experimental results}

In this section, some meaningful experiments are presented and discussed. The time series, see Table 1 , is pre-processed to reduce speckle using a $3 \times 3$ average moving window. The first experiment analyses the backscattered signal measured over slick-free and oiled sea surface at different polarizations and AOI, including the effects of noise. The second experiment aims at providing a physical understanding of slick-free sea and oil seep backscattering for varying polarization and $\mathrm{AOI}$ using the backscattering model described in section 3; the third experiment oil/sea separability is discussed against WS, polarization, AOI, and NESZ; while the fourth experiment aims at analysing the temporal variability of the oil seep.

\subsection{Multi-polarization data analysis}

The first experiment consists of randomly sampling 1000 pixels belonging to slick-free and oiled region of interests (ROIs) excerpted over the whole time series, i.e., slick-free and oiled ROls are excerpted from each SAR scene. The mean and standard deviation of the $\mathrm{HH}$ - and VV-polarized NRCS related to slick-free and oil-covered ROIs ( $\sigma_{\mathrm{HH}}^{0}$ and $\sigma_{\mathrm{VV}}^{0}$ ) are plotted according to the three subsets identified in Table 1, i.e., the data points are grouped according to the AOI of the SAR imagery and are depicted in blue (slick-free) and red (oil-covered), see Figure 5(a,b), respectively. To better understand the role of sensor and environmental parameters on the backscattering from the oil seep, 


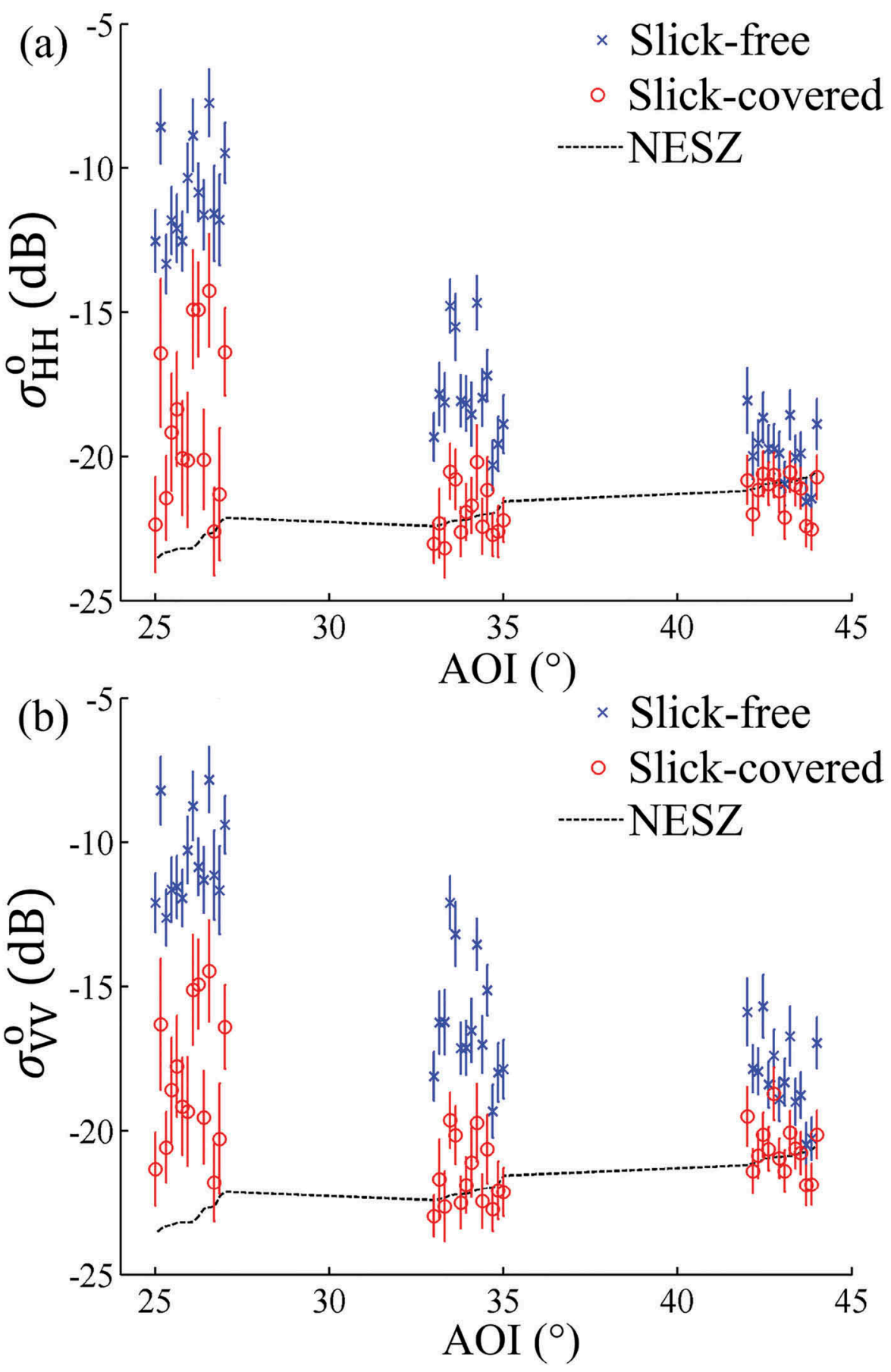

Figure 5. Mean and standard deviation values of: (a) $\sigma_{\mathrm{HH}}^{0}$ and (b) $\sigma_{\mathrm{VV}}^{0}$, evaluated within slick-free (blue error bars with cross markers) and oil-covered (red error bars with circle markers) ROIs excerpted over the whole TSX SAR imagery time series. The data points shown are grouped according to the AOI of the SAR subset they belong to, see Table 1. The NESZ curve is also depicted in black dashed line for reference purposes. 
a preliminary analysis of slick-free sea surface backscattering is due. When dealing with the $\mathrm{HH}$ channel, it could be noted that $\sigma_{\mathrm{HH}}^{0}$ decreases for increasing AOI, as expected, since a tilted-Bragg scattering model applies. For a given AOI, slick-free NRCS exhibits a non-negligible variability. This variability (hereinafter referred as intra-field variability) is likely due to the different sea state conditions during the TSX images acquisition. The intra-field variability is almost the same for all AOls. To quantitatively analyse the $\mathrm{HH}-$ polarized backscattering behaviour, mean and standard deviation values of $\sigma_{\mathrm{HH}}^{0}$ belonging to each $\mathrm{AOI}$ are listed in Table 2. Experimental results confirm that, over slick-free sea surface, the main backscattering reduction applies in the $\mathrm{AOI}$ range $26^{\circ}-34^{\circ}$ (about 7.0 $\mathrm{dB}$ ), also confirming the similar intra-field variability at all the AOI. However, as it will be discussed, the different trends observed at AOls larger than $34^{\circ}$ can be related to the strong impact of noise (SNR below $3 \mathrm{~dB}$ for both $\mathrm{HH}$ and $\mathrm{V}$ channels).

With respect to oil-covered sea surface backscattering, the mean NRCS values are always lower than the corresponding slick-free ones. There is a significant difference between oilcovered NRCS values evaluated over the subset at $\mathrm{AOI}=26^{\circ}, \mathrm{AOI}=34^{\circ}$, and $\mathrm{AOI}=43^{\circ}$. The largest difference applies at low incidence angles and reduces when increasing $A O I$. Even oil-covered NRCS exhibits an intra-field variability, which is likely due to the fact that the oilcovered area observed by TSX imagery belonging to the same subset is not always the same. In addition, the damping properties of the oil layer change in space and time due to meteo-marine conditions. This variability decreases with increasing incidence angle even considering that for AOls larger than $26^{\circ}$, the role played by the noise tends to be dominant (SNR significantly below $3 \mathrm{~dB}$ ). A more quantitative analysis is provided in Table 2 where the mean and standard deviation values of oil-covered NRCS are listed for each AOI. The NRCS decreases from $\mathrm{AOI}=26^{\circ}$ to $\mathrm{AOI}=34^{\circ}$ (about $3.0 \mathrm{~dB}$ ); while it exhibits similar values for $\mathrm{AOI}$ $=34^{\circ}$ and $\mathrm{AOI}=43^{\circ}$. The same trend applies for its standard deviation, i.e., the intra-field variability reduces for increasing $\mathrm{AOI}$. Even in this case, this global trend is mainly due to the effects of noise, as it will be discussed. The behaviour of VV-polarized backscattering is depicted in Figure 5(b). The slick-free/oil-covered trend with respect to AOI is similar to the $\mathrm{HH}$-polarized one (see Figure 5(a)).

To interpret SAR imagery of oil seeps, SNR must be accounted for. Hence, the NESZ profile of each imagery is extracted with reference to the location (i.e., range and azimuth of the considered slick-covered ROI). All the extracted profiles are first averaged over each image and then interpolated over the three AOls to obtain the average

Table 2. Mean and standard deviation values of $\sigma_{\mathrm{HH}}^{0}$ and $\sigma_{\mathrm{VV}}^{0}$ over clean ocean and oil seep evaluated for the three SAR data subsets partitioned according to their mean AOI. The mean SNR values are also listed.

\begin{tabular}{llccc}
\hline & & \multicolumn{3}{c}{$\mathrm{AOI}\left({ }^{\circ}\right)$} \\
\cline { 3 - 5 } ROI & Parameter $(\mathrm{dB})$ & 26 & 34 & 43 \\
\hline Sea & $\sigma_{\mathrm{HH}}^{0}$ & $-11.3 \pm 1.9$ & $-18.1 \pm 2.0$ & $-20.1 \pm 1.3$ \\
& $\mathrm{SNR}$ & 10.9 & 3.4 & 0.3 \\
& $\sigma_{\mathrm{VV}}^{0}$ & $-11.0 \pm 1.8$ & $-17.0 \pm 2.2$ & $-18.5 \pm 1.7$ \\
& SNR & 11.3 & 4.9 & 1.8 \\
Oil & $\sigma_{\mathrm{HH}}^{0}$ & $-19.1 \pm 3.1$ & $-22.1 \pm 1.2$ & $-21.3 \pm 0.9$ \\
& SNR & 2.3 & -0.8 & -1.1 \\
& $\sigma_{\mathrm{VV}}^{0}$ & $-18.6 \pm 2.7$ & $-21.9 \pm 1.3$ & $-20.8 \pm 1.0$ \\
& SNR & 3.2 & -0.5 & -0.7 \\
\hline
\end{tabular}


behaviour of the noise among the whole time series. The result is depicted as a black dashed line in Figure 5.

It can be noted that, when dealing with slick-free sea surface, both $\sigma_{\mathrm{HH}}^{0}$ and $\sigma_{\mathrm{V}}^{0}$ tend to approach the NESZ for increasing AOI. In detail, the SNR is well-above the $3.0 \mathrm{~dB}$ threshold at low AOI. This means that surface backscattering is reliable at $A O I$ about $26^{\circ}$. As far as $A O I$ increases (AOI about $34^{\circ}$ ), the SNR of both channels approaches the $3.0 \mathrm{~dB}$ threshold making the physical interpretation of sea backscattering less reliable, and goes below the threshold at $\mathrm{AOI}=43^{\circ}$ for both $\mathrm{HH}$ and $\mathrm{V}$ channels, see Table 2 . This means that at larger AOIs, i.e., $>34^{\circ}$, the noise significantly corrupts the measured signal even over slick-free sea surface.

When dealing with slick-covered sea surface, it can be noted that the signal backscattered off sea oil seeps is severely affected by noise. The HH-polarized NRCS falls below the $3 \mathrm{~dB}$ threshold since $26^{\circ}$, while oil seep backscattering in VV channel is noisecorrupted for AOls $>26^{\circ}$, see Table 2 . This analysis points out that slick-free (slickcovered) backscattered signal measured by TSX SAR antenna is reliable in both copolarized channels at AOIs $\leq 34^{\circ}$ (in VV channel only, at AOI about $26^{\circ}$ ).

This behaviour affects the oil/sea separation that, according to Figure 5, decreases for increasing AOI. This result agrees with the one obtained in (Skrunes et al. 2015), where it was found that the oil/sea separability in terms of $\sigma_{V V}^{0}$ sea/oil contrast reduces (of about $2.5 \mathrm{~dB}$ ) when $\mathrm{AOI}$ increases from about $28^{\circ}$ up to about $41^{\circ}$. Nonetheless, this result differs from model's predictions in (Pinel, Bourlier, and Sergievskaya 2014) and experimental results in (Minchew, Jones, and Holt 2012) that showed a sea/oil contrast increasing with AOI under intermediate incidence angles. This is likely due to the significantly lower NESZ that characterizes UAVSAR (Unmanned Aerial Vehicle SAR) measurements if compared to the TSX ones (Minchew, Jones, and Holt 2012; Latini, Del Frate, and Jones 2016). In operational exploitation of large time series of SAR imagery for sea oil seep monitoring, this result has remarkable implications. In fact, is typically considered that the lower backscattering over the oil slicks and the noisy measurements resulting from the oil slick concur to enhance the oil slick identification (Migliaccio, Nunziata, and Buono 2015). The above-described result witnesses this is not always true since even sea surface backscattering is affected by noise at larger AOls.

\subsection{Model-based backscattering analysis}

The second experiment consists of interpreting backscattering from oil seep using the twoscale scattering model previously described. Again, to better understand the behaviour of oil seep backscattering, a preliminary analysis on slick-free sea surface is provided, discussing the behaviour of slick-free data points with respect to AOI and predicting slick-free backscattering using the two-scale scattering model. Model parameters adopted to predict slick-free and oil-covered sea surface backscattering are summarized in Table 3.

The predicted $\sigma_{\mathrm{VV}}^{0}$ related to slick-free sea surface is shown in magenta in Figure 6(a), where the data points of Figure 5(b) are also annotated in blue colour together with a polynomial data fitting (see black dashed line). The fitting is based on a two-term power series model, i. e., $y=a x^{b}+c$ (coefficient of determination, $R^{2}=0.77$, and root mean square error, RMSE $=1.77$ ). It can be noted that, as expected, there is a fairly good 
Table 3. Backscattering model parameters.

\begin{tabular}{lc}
\hline Parameter & Value \\
\hline Radar frequency $(\mathrm{GHz})$ & 9.6 \\
Radar polarization & $\mathrm{V}$ \\
AOI range $\left(^{\circ}\right)$ & $25-50$ \\
Fetch $\left(\mathrm{km}^{2}\right)$ & 500 \\
$X-\mathrm{MOD} \mathrm{WS}\left(\mathrm{m} \mathrm{s}^{-1}\right)$ & 5 \\
$\mathrm{SST}\left({ }^{\circ} \mathrm{C}\right)$ & 30 \\
$\mathrm{SSS}(\mathrm{psu})$ & 35 \\
$\epsilon_{\mathrm{W}}$ & $58.19-\mathrm{j} 33.13$ \\
$|E|\left(\mathrm{N} \mathrm{m}^{-1}\right)$ & 0.0225 \\
$\varphi\left({ }^{\circ}\right)$ & -175 \\
$\epsilon_{\mathrm{o}}$ & $2.10-\mathrm{j} 0.02$ \\
\hline
\end{tabular}

agreement between measurements and model predictions, with the exception of $\mathrm{AOI}=$ $34^{\circ}$ where model predictions tend to overestimate actual measurements. This is likely due to the wind conditions of the data points at $\mathrm{AOI}=34^{\circ}$ that call for an average WS lower than $5.0 \mathrm{~ms}^{-1}$, see Table 1 .

To further verify the soundness of the obtained results, the X-band Geophysical Model Function (GMF), namely X-MOD, developed in (Li and Lehner 2013) is considered to predict $\sigma_{\mathrm{VV}}^{0}$ using the average WS extracted from the TSX SAR imagery time series, i.e., $5.0 \mathrm{~ms}^{-1}$. The GMF output is shown in Figure $6(\mathrm{a})$ as a continuous black line. It can be noted that there is a fairly good agreement between the two-scale model prediction and the GMF. Their distance is negligible for AOIs up to $45^{\circ}$ while it increases at larger AOls. Note also that even the GMF overestimates NRCS values at $\mathrm{AOI}=34^{\circ}$ witnessing that a lower WS applies for this subset.

The NRCS related to the oil seep is predicted using the theoretical rationale described in Figure 4 and the results are shown in Figure $6(b-c) . \sigma_{\mathrm{VV}}^{0}$ is first predicted considering the surface-effect of the oil seep only (i.e., damping and reduction of the friction velocity), see Figure $6(b)$; then, the oil/water mixture is considered, see Figure $6(\mathrm{c})$. The surface effects of the oil seep are taken into account using three different $\beta$ values (see Equation (7)), i.e., 0.3, 0.5, and 0.7. The three curves are plotted versus the AOI in Figure $6(\mathrm{~b})$, where they are shown in asterisked, circled and continuous magenta lines, respectively. The data points related to the actual NRCS values measured considering the three SAR imagery subsets are also annotated (in red) together with the polynomial fitting curve, in dashed black, that best fits the data points $\left(R^{2}=0.31\right.$, RMSE $\left.=1.83\right)$. Experimental results show that there is no $\beta$ value that results in a satisfactory fitting for all the AOls. This is likely due to the fact that at low AOls the data points exhibit a large intra-field variability, while at AOI larger than $40^{\circ}$ data points are not reliable since noise dominates. A fairly good agreement is achieved using $\beta=0.3$ at $\mathrm{AOI}=34^{\circ}$. This result agrees with experiments undertaken on a X-band SAR imagery time series collected during an oil rig accident off the Aberdeen coasts, United Kingdom (Montuori et al. 2016).

To analyse the effects of the oil/water mixture, $\epsilon_{\text {eff }}$ is included into the backscattering model to predict $\sigma_{\mathrm{VV}}^{0}$ related to the oil seep (see Equation (9)). Results are depicted in Figure 6 (c) where $\beta=0.7$ and three $\delta_{\mathrm{i}}$ values are used, i.e., $0.1,0.3$, and 0.5 . It must be pointed out that those values may not correspond to the actual oil volume fraction, but they allow us 

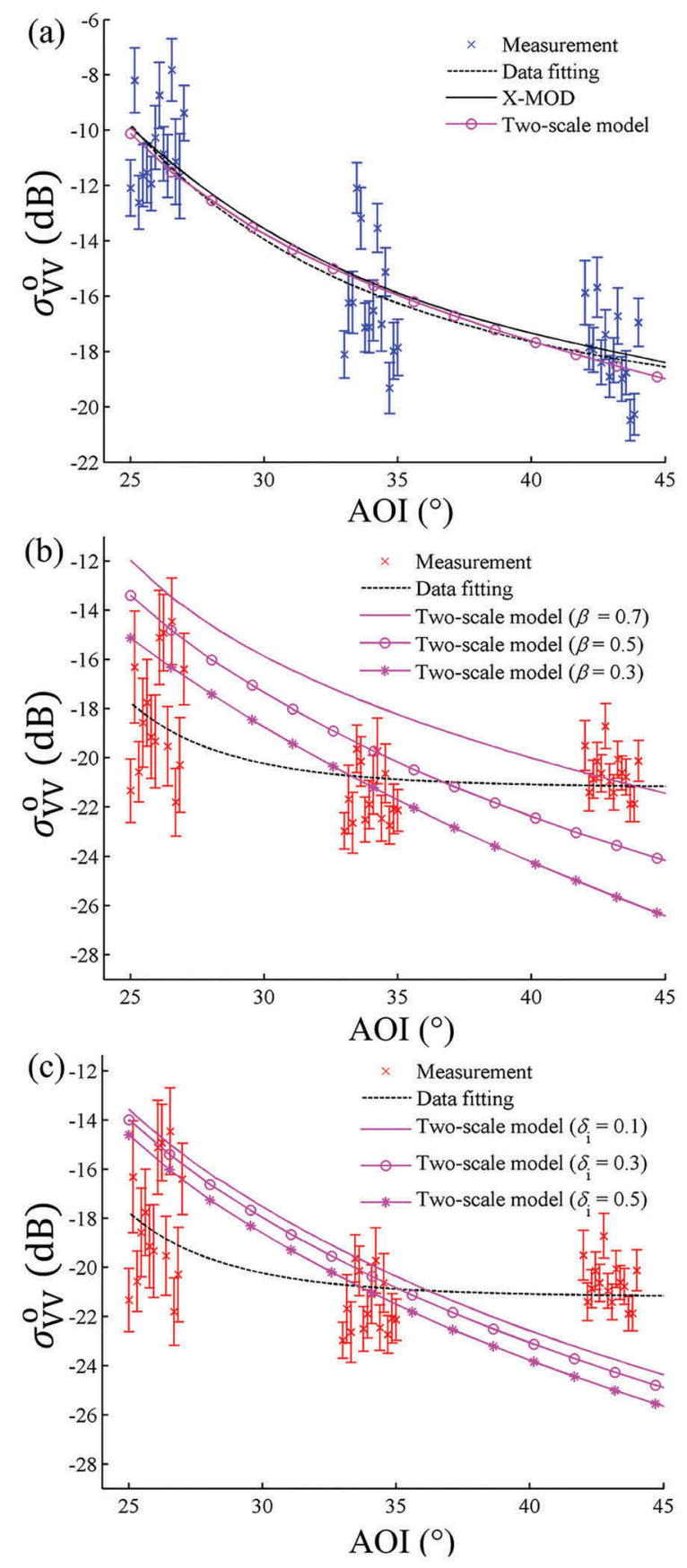

Figure 6. VV-polarized NRCS backscattering analysis: (a) slick-free sea surface; (b) slick-covered sea surface modelled using different $\beta$ values; (c) oil/water mixture modelled using different $\delta_{\mathrm{i}}$ values.

quantitatively assessing the effects of oil volume fraction on the VV-polarized backscattering. The three curvers are plotted versus AOI in continuous, circled and asterisked magenta lines, respectively. It can be noted that, as expected, the backscattered signal reduces when 
increasing the oil volume fraction. Even in this case, a fairly good agreement between model's predictions and data points can be observed at $\mathrm{AOI}=34^{\circ}$.

\subsection{Multi-polarization sea oil seep observation}

The third experiment aims at analysing oil/sea separability against radar polarization, AOI and WS.

To analyse oil/sea separability with respect to WS, two non-overlapped wind regimes are identified: low wind (i.e., WS $\leq 3.5 \mathrm{~ms}^{-1}$ ) and moderate wind (i.e., WS $\geq 5.0 \mathrm{~ms}^{-1}$ ), see Table 1. Then, for each SAR subset, the empirical probability density function (pdf) of NRCS values belonging to slick-free and oiled ROIs is evaluated and the Bhattacharyya distance $D_{\mathrm{B}}$ (Kailath 1967) is measured between slick-free and oil-covered pdfs, see Table 4, where $D_{\mathrm{B}}$ mean and standard deviation values are listed. The largest $D_{\mathrm{B}}$ is provided by $\sigma_{\mathrm{VV}}^{0}$ for each AOI and for any WS.

It can be also noted that $D_{\mathrm{B}}$ decreases for increasing $\mathrm{AOI}$ and the largest distance is achieved under moderate wind regime. In addition, it is clear that the noise significantly affects separability at AOls $>34^{\circ}$. In fact, oil/sea separability reduces for both channels of more than $50 \%$ when moving from $34^{\circ}$ to $43^{\circ}$. Among the polarimetric channels, as expected, the $\mathrm{VV}$ one provides slightly better results than the $\mathrm{HH}$ one.

\subsection{Time evolution of the polluted area}

The fourth experiment aims at estimating the oil-affected sea surface area exploiting the whole time series of TSX SAR imagery. The detection of the see oil seep is undertaken using the approach proposed in (Migliaccio, Nunziata, and Gambardella 2009; Velotto et al. 2011). The latter relies on the capability of coherent HH-VV SAR data to emphasize the presence of an oil slick with respect to the surrounding sea in a very effective and robust way. Basically, the standard deviation of the phase difference between $\mathrm{HH}$ and $\mathrm{VV}$ channel is evaluated that can be considered as an unbiased estimator of the correlation between the copolarized channels. The sea surface area affected by the oil seep is expected to call for a more depolarizing scattering if compared to the clean sea. Hence, the oil-affected area

Table 4. Mean and standard deviation values of the Bhattacharyya distance $\left(D_{B}\right)$ between oil seep and clean ocean relevant to the empirical pdfs of $\mathrm{HH}$ and $\mathrm{VV}$ channels. According to Table 1, different AOls and wind regimes are considered.

\begin{tabular}{lcc}
\hline \multicolumn{3}{c}{$D_{B}$} \\
\hline & \multicolumn{2}{c}{ Low wind $\left(W S \leq 3.5 \mathrm{~m} \mathrm{~s}^{-1}\right)$} \\
\cline { 2 - 3 } AOI $\left({ }^{\circ}\right)$ & $\mathrm{HH}$ & $\mathrm{VV}$ \\
\hline 26 & $0.88 \pm 0.15$ & $0.95 \pm 0.17$ \\
34 & $0.53 \pm 0.01$ & $0.77 \pm 0.04$ \\
43 & $0.18 \pm 0.03$ & $0.31 \pm 0.02$ \\
\hline \multicolumn{3}{c}{ Moderate wind $\left(\mathrm{WS} \geq 5.0 \mathrm{~m} \mathrm{~s}^{-1}\right)$} \\
\cline { 2 - 3 } & $\mathrm{HH}$ & $\mathrm{VV}$ \\
\hline 26 & $1.04 \pm 0.23$ & $1.14 \pm 0.22$ \\
43 & $0.95 \pm 0.29$ & $1.16 \pm 0.32$ \\
\hline
\end{tabular}




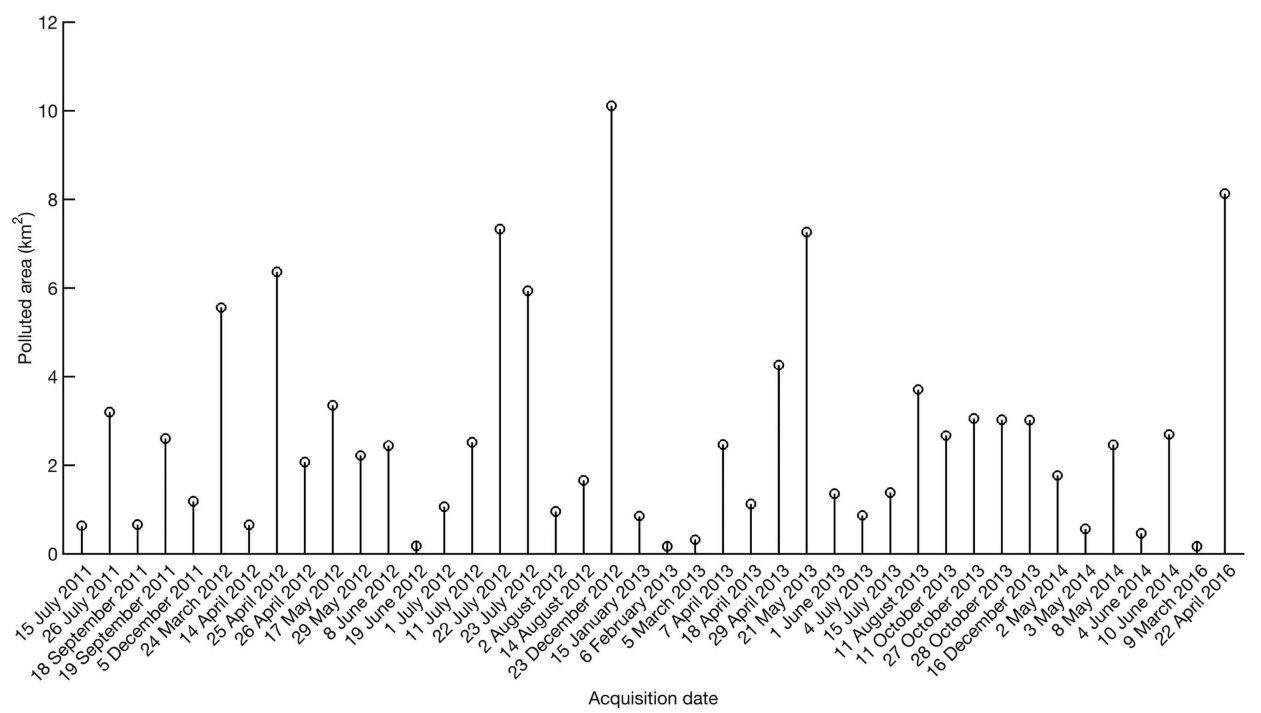

Figure 7. Extent of the polluted sea surface area estimated from the multi-polarization TSX time series.

results in significantly lower HH-W correlation and, in turn, very larger CPD standard deviation values (Migliaccio, Nunziata, and Gambardella 2009; Velotto et al. 2011).

The processing consists of evaluating the standard deviation of the phase difference between the co-polarized channel for each SAR scene. Then, a binary map is obtained using an empirical threshold (equal to $90^{\circ}$ ). Finally, the area of the polluted sea surface is evaluated. Results are shown in Figure 7 where a uniform spacing is used along the $x$-axis in order to better appreciate results. It can be noted that the analysis of the 42 excerpts of TSX imagery collected in the period July 2011 - April 2016 results in an average daily polluted area of $2.7 \mathrm{~km}^{2}$. This result agrees with the '2017 Cumulative Spill Report' published by SkyTruth for the Taylor Energy site, where an average daily extent of the polluted area of $3.0 \mathrm{~km}^{2}$ was recorded for the period 2011-2014 (Covington 2017). Note that 40 out of the 42 TSX scenes in that period were collected.

Figure 7 further witnesses the inherent random nature of the oil seepage manifestations. The extent of the polluted area significantly varies along the whole time series, resulting in a standard deviation of $2.4 \mathrm{~km}^{2}$. Similar results, i.e., a standard deviation of $1.5 \mathrm{~km}^{2}$, was found for the period 2011-2014 in (Covington 2017). It must be also pointed out that non-negligible changes occur on a daily basis, see, for instance, the oilaffected sea surface area estimation relevant to the SAR acquisitions of 18 and 19 September 2011 (25 and 26 April 2012), whose extent increases (decreases) from less than $1.0 \mathrm{~km}^{2}$ up to almost $3.0 \mathrm{~km}^{2}$ (more than $6.0 \mathrm{~km}^{2}$ down to $2.0 \mathrm{~km}^{2}$ ).

\section{Conclusions}

In this study, a large time series of 42 dual-polarimetric (HH and VV) SAR measurements, collected by the TSX mission, is exploited to observe the well-known oil seepage related to the Taylor Energy oil drilling platform site in the Gulf of Mexico. The analysis is undertaken to determine the effects of SAR acquisition parameters (AOI, NESZ) and 
environmental conditions (WS, damping, oil volume concentration) on singlepolarization SAR oil seep observation in order to assess the reliability of the time series. The two-scale BPM scattering model is adopted to provide a physical framework that supports a better understanding of the role played by those factors.

Summarizing, the main outcomes are as follows:

- The high NESZ that characterizes TSX strongly limits a reliable interpretation of the slick-free sea surface and oil seep backscattering evaluated along the time series at larger AOls;

- At AOls $>34^{\circ}\left(26^{\circ}\right), \mathrm{HH}$ - and VV-polarized sea surface (VV-polarized oil seep) backscattering is significantly corrupted by noise; this means that oil/sea separability is noise-affected. Note that this has also important operational implications since, typically, the lower oil backscattering and noise-affected measurements are considered to jointly concur in improving polarimetric SAR-based sea oil slick detection (Migliaccio, Nunziata, and Buono 2015, Migliaccio, Nunziata, and Gambardella 2009);

- Under low-to-moderate conditions, HH and VV channels provide almost the same oil/sea separation which is not significantly influenced by WS;

- A reliable analysis of oil backscattering can be undertaken at lower AOIs (i.e., $<34^{\circ}$ ) in VV channel only, when it is shown that the backscattering from an oil seep is affected by the oil's damping properties more than its concentration in the water column;

- An average daily polluted area of $2.7 \mathrm{~km}^{2}$ was estimated from the co-polarized TSX time series. The area polluted by the oil varies significantly on a daily basis.

\section{Acknowledgments}

This study is partly funded by the Università degli Studi di Napoli Parthenope, project ID DING202 and by the European Space Agency (ESA) within the frame of ESA-MOST (Ministry of Science and Technology) Dragon 4 Cooperation ("Microwave satellite measurements for coastal area and extreme weather monitor", project ID 32235). We thank the German Space Agency (DLR) that has provided the TerraSAR-X SAR data under the AO OCE1045 and to National Oceanic and Atmospheric Administration (NOAA) that provided buoy data freely available. We would also like to thank Prof. P. Sobieski, Université Catholique de Louvain, who provided the BPM software code, and $\operatorname{Dr}$ O. Garcia-Pineda for the useful discussions on the Taylor Energy oil seep.

\section{Disclosure statement}

No potential conflict of interest was reported by the authors.

\section{Funding}

This study is partly funded by the Università degli Studi di Napoli Parthenope, project ID DING202 and by the European Space Agency (ESA) within the frame of ESA-MOST (Ministry of Science and Technology) Dragon 4 Cooperation ("Microwave satellite measurements for coastal area and extreme weather monitor", project ID 32235). 


\section{ORCID}

F. Nunziata (1) http://orcid.org/0000-0003-4567-0377

C. R. de Macedo (i) http://orcid.org/0000-0001-6732-9554

A. Buono (i) http://orcid.org/0000-0002-5523-7609

D. Velotto (D) http://orcid.org/0000-0002-8592-0652

M. Migliaccio (1) http://orcid.org/0000-0002-8363-3502

\section{References}

Alpers, W., B. Holt, and K. Zeng. 2017. "Oil Spill Detection by Imaging Radars: Challenges and Pitfalls." Remote Sensing of Environment 201: 133-147. doi:10.1016/j.rse.2017.09.002.

Boukabara, S. A., L. Eymard, C. Guillou, D. Lemaire, P. Sobieski, and A. Guissard. 2002. "Development of a Modified Two-Scale Electromagnetic Model Simulating Both Active and Passive Microwave Measurements: Comparison to Data Remotely Sensed over the Ocean." Radio Science 37 (4): 16-1-16-11. doi:10.1029/1999RS002240.

Brekke, C., B. Holt, C. Jones, and S. Skrunes. 2014. "Discrimination of Oil Spills from Look-Alikes in the Marginal Ice Zone by Synthetic Aperture Radar." Remote Sensing of Environment 145: 1-14. doi:10.1016/j.rse.2014.01.015.

Brekke, C., C. E. Jones, S. Skrunes, B. Holt, M. Espeseth, and T. Eltoft. 2016. "Cross-Correlation between Polarization Channels in SAR Imagery over Oceanographic Features." IEEE Geoscience and Remote Sensing Letters 13 (7): 997-1001. doi:10.1109/LGRS.2016.2558543.

Brekke, C., and A. H. S. Solberg. 2005. "Oil Spill Detection by Satellite Remote Sensing." Remote Sening of Environment 95 (1): 1-13. doi:10.1016/j.rse.2004.11.015.

Buono, A., F. Nunziata, M. Migliaccio, and X. Li. 2016. "Polarimetric Analysis of Compact-Polarimetry SAR Architectures for Sea Oil Slick Observation." IEEE Transactions on Geoscience and Remote Sensing 54 (10): 5862-5874. doi:10.1109/TGRS.2016.2574561.

Cheng, Y., B. Liu, X. Li, F. Nunziata, Q. Xue, X. Ding, M. Migliaccio, and W. G. Pichel. 2014. "Monitoring of Oil Spill Trajectories with COSMO-SkyMed X-Band SAR Images and Model Simulation." IEEE Journal of Selected Topics in Applied Earth Observation and Remote Sensing 7 (7): 2895-2901. doi:10.1109/JSTARS.2014.2341574.

Covington, R. 2017. Taylor Energy (Site 23051) Cumulative Spill Report - 2017 Update." SkyTruth. https://www.skytruth.org/2017/12/taylor-energy-site-23051-cumulative-spill-report-2017-update/.

de Miranda, F. P., A. M. Q. Marmol, E. C. Pedroso, C. H. Beisl, P. Welgan, and L. Morales. 2004. "Analysis of RADARSAT-1 Data for Offshore Monitoring Activities in the Cantarell Complex, Gulf of Mexico, Using the Unsupervised Semivariogram Textural Classifier (USTC)." Canadian Journal of Remote Sensing 30 (3): 424-436. doi:10.5589/m04-019.

Del Frate, F., A. Petrocchi, J. Lichtenegger, and G. Calabresi. 2000. "Neural Networks for Oil Spill Detection Using ERS-SAR Images." IEEE Transactions on Geoscience and Remote Sensing 38 (5): 2282-2287. doi:10.1109/36.868885.

Eineder, M., T. Fritz, J. Mittermayer, A. Roth, E. Boerner, and H. Breit. 2008. "TerraSAR-X Ground Segment, Basic Product Specification Document." In TX-GS-DD-3302 Cluster Applied Remote Sensing (CAF) 1.5, Technical Report Published by the German Space Agency (DLR) on 24 February 2008, edited by T. Fritz and M. Eineder, 1.5, 1-103. Oberpfaffenhofen, Germany.

Elfouhaily, T., B. Chapron, K. Katsaros, and D. Vandemark. 1997. "A Unified Directional Spectrum for Long and Short Wind-Driven Waves." Journal of Physical Research 102 (C7): 15781-15796. doi:10.1029/97JC00467.

Ellison, W., A. Balana, G. Delbos, K. Lamkaouchi, L. Eymard, C. Guillou, and C. Prigent. 1998. "New Permittivity Measurements of Seawater." Radio Science 33 (3): 639-648. doi:10.1029/97RS02223.

Fingas, M. 2018. "The Challenges of Remotely Measuring Oil Slick Thickness." Remote Sensing 10: 319-347. doi:10.3390/rs10020319. 
Friiso, T., Y. Schildberg, O. Rambeau, T. Tjomsland, H. Fordedal, and J. Sjoblom. 1998. "Complex Permittivity of Crude Oils and Solutions of Heavy Crude Oil Fractions." Journal of Dispersion Science and Technology 19 (1): 93-126. doi:10.1080/01932699808913163.

Gade, M., W. Alpers, H. Huhnerfuss, H. Masuko, and T. Kobayashi. 1998. "Imaging of Biogenic and Anthropogenic Ocean Surface Films by the Multifrequency/Multipolarization SIR-C/X-SAR." Journal of Physical Research 103 (C9): 18851-18866. doi:10.1029/97JC01915.

Gambardella, A., G. Giacinto, M. Migliaccio, and A. Montali. 2010. "One-Class Classification for Oil Spill Detection." Pattern Analysis and Applications 13: 349-366. doi:10.1007/s10044-009-0164-z.

Garcia-Pineda, O., J. Holmes, M. Rissing, R. Jones, C. Wobus, J. Svejkovsky, and M. Hess. 2017. "Detection of Oil near Shorelines during the Deepwater Horizon Oil Spill Using Synthetic Aperture Radar (SAR)." Remote Sensing 9: 567-586. doi:10.3390/rs9060567.

Garcia-Pineda, O., B. Zimmer, M. Howard, W. G. Pichel, X. Li, and I. R. MacDonald. 2009. “Using SAR Images to Delineate Ocean Oil Slicks with a Texture-Classifying Neural Network Algorithm (TCNNA)." Canadian Journal of Remote Sensing 35 (5): 411-421. doi:10.5589/m09-035.

Gesteira, J. L. G., and J. C. Dauvin. 2000. "Amphipods are Good Bioindicators of the Impact of Oil Spills on Soft-Bottom Macrobenthic Communities." Marine Pollution Bulletin 40 (11): 1017-1027. doi:10.1016/S0025-326X(00)00046-1.

Girard-Ardhuin, F., G. Mercier, F. Collard, and R. Garello. 2005. "Operational Oil-Slick Characterization by SAR Imagery and Synergistic Data." IEEE Journal of Oceanic Engineering 30 (3): 487-495. doi:10.1109/JOE.2005.857526.

Guissard, A., P. Sobieski, and C. Baufays. 1992. "A Unified Approach to Bistatic Scattering for Active and Passive Remote Sensing of Rough Ocean Surfaces." Trends in Geophysical Research 1: 43-68.

Gulf Monitoring Consortium. 2011. "Report on Activities from April 2011 to October 2011." Technical Report Co-published by the Partners of the Gulf Monitoring Consortium Composed by SkyTruth, SouthWings, Waterkeeper Alliance and Lower Mississippi Riverkeeper. Accessed 12 March 2018. https://skytruth.org/gmc/wp-content/uploads/2012/05/Gulf-Monitoring-Consortium-Report.pdf

Ivonin, D. V., S. Skrunes, C. Brekke, and A. Y. Ivanov. 2016. "Interpreting Sea Surface Slicks on the Basis of the Normalized Radar Cross-Section Model Using RADARSAT-2 Copolarization Dual-Channel SAR Images." Geophysical Research Letters 43 (6): 2748-2757. doi:10.1002/ 2016 GL068282.

Jatiault, R., D. Dhont, L. Loncke, and D. Dubucq. 2017. "Monitoring of Natural Oil Seepage in the Lower Congo Basin Using SAR Observations." Remote Sensing of Environment 191: 258-272. doi:10.1016/j.rse.2017.01.031.

Kailath, T. 1967. "The Divergence and Bhattacharyya Distance Measures in Signal Selection." IEEE Transactions on Communication Technology 15 (1): 52-60. doi:10.1109/TCOM.1967.1089532.

Korber, J. -. H., H. Sahling, T. Pape, C. Dos Santos Ferreira, I. MacDonald, and G. Bohrmann. 2014. "Natural Oil Seepage at Kobuleti Ridge, Eastern Black Sea." Marine and Petroleum Geology 50: 68-82. doi:10.1016/j.marpetgeo.2013.11.007.

Latini, D., F. Del Frate, and C. E. Jones. 2016. "Multi-Frequency and Polarimetric Quantitative Analysis of the Gulf of Mexico Oil Spill Event Comparing Different SAR Systems." Remote Sensing of Environment 183: 26-42. doi:10.1016/j.rse.2016.05.014.

Leifer, I., W. J. Lehr, D. Simecek-Beatty, E. Bradley, R. Clark, P. Dennison, Y. Hu, et al. 2012. "State of the Art Satellite and Airborne Marine Oil Spill Remote Sensing: Application to the BP Oil Spill." Remote Sensing of Environment 124: 185-209. doi:10.1016/j.rse.2012.03.024.

Li, X. -. M., and S. Lehner. 2013. "Algorithm for Sea Surface Wind Retrieval from TerraSAR-X and TanDEM-X Data." IEEE Transactions on Geoscience and Remote Sensing 52 (5): 2928-2939. doi:10.1109/TGRS.2013.2267780.

Lombardini, P., B. Fiscella, P. Trivero, C. Cappa, and W. Garrett. 1989. "Modulation of the Spectra of Short Gravity Waves by Sea Surface Films: Slick Detection and Characterization with a Microwave Probe." Journal of Atmospheric and Oceanic Technology 6 (6): 882-890. doi:10.1175/1520-0426(1989)006<0882:MOTSOS>2.0.CO;2.

Mallet, P., C. A. Guerin, and A. Sentenac. 2005. "Maxwell-Garnett Mixing Rule in the Presence of Multiple Scattering: Derivation and Accuracy." Physical Review B 72 (1): 14-25. doi:10.1103/ PhysRevB.72.014205. 
Meissner, T., and F. J. Wentz. 2004. "The Complex Dielectric Constant of Pure and Sea Water from Microwave Satellite Observations." IEEE Transactions on Geoscience and Remote Sensing 42 (9): 1836-1849. doi:10.1109/TGRS.2004.831888.

Mera, D., V. Bolon-Canedo, J. M. Cotos, and A. Alonso-Betanzos. 2017. "On the Use of Feature Selection to Improve the Detection of Sea Oil Spills in SAR Images." Computer Geoscience 100 (C): 166-178. doi:10.1016/j.cageo.2016.12.013.

Migliaccio, M., A. Gambardella, F. Nunziata, M. Shimada, and O. Isoguchi. 2009b. "The PALSAR Polarimetric Mode for Sea Oil Slick Observation." IEEE Transactions on Geoscience and Remote Sensing 47 (12): 4032-4041. doi:10.1109/TGRS.2009.2028737.

Migliaccio, M., and F. Nunziata. 2014. "On the Exploitation of Polarimetric SAR Data to Map Damping Properties of the Deepwater Horizon Oil Spill." International Journal of Remote Sensing 35 (10): 3499-3519. doi:10.1080/01431161.2014.905730.

Migliaccio, M., F. Nunziata, C. E. Brown, B. Holt, X. Li, W. G. Pichel, and M. Shimada. 2012. "Polarimetric Synthetic Aperture Radar Utilized to Track Oil Spills." Transactions on EOS 93 (16): 161-163. doi:10.1029/2012EO160001.

Migliaccio, M., F. Nunziata, and A. Buono. 2015. "SAR Polarimetry for Sea Oil Slick Observation." International Journal of Remote Sensing 36 (12): 3243-3273. doi:10.1080/01431161.2015.1057301.

Migliaccio, M., F. Nunziata, and A. Gambardella. 2009. "On the Co-Polarised Phase Difference for Oil Spill Observation." International Journal of Remote Sensing 30 (6): 1587-1602. doi:10.1080/ 01431160802520741.

Minchew, B. 2012. "Determining the Mixing of Oil and Sea Water Using Polarimetricsynthetic Aperture Radar." Geophysical Research Letters 39 (16): 1-6. doi:10.1029/2012GL052304.

Minchew, B., C. E. Jones, and B. Holt. 2012. "Polarimetric Analysis of Backscatter from the Deepwater Horizon Oil Spill Using L-Band Synthetic Aperture Radar." IEEE Transactions on Geoscience and Remote Sensing 50 (10): 3812-3830. doi:10.1109/TGRS.2012.2185804.

Montuori, A., F. Nunziata, M. Migliaccio, and P. Sobieski. 2016. "X-Band Two-Scale Sea Surface Scattering Model to Predict the Contrast Due to an Oil Slick." IEEE Journal of Selected Topics in Applied Earth Observation and Remote Sensing 9 (11): 4970-4978. doi:10.1109/ JSTARS.2016.2605151.

National Oceanic and Atmospheric Administration (NOAA). 2017. "NOAA National Data Buoy Center." Accessed 25 February 2018. http://www.ndbc.noaa.gov/

National Research Council (US) Committee on Oil in the Sea. 2003. Oil in the Sea III: Inputs, Fates, and Effects. Washington, DC: National Academies Press (US). http://www.ncbi.nlm.nih.gov/ books/NBK220703/.

Nunziata, F., A. Buono, and M. Migliaccio. 2018. "COSMO-SkyMed Synthetic Aperture Radar Data to Observe the Deepwater Horizon Oil Spill." Sustainability 10 (10): 3599. doi:10.3390/ su.10103599.

Nunziata, F., P. Sobieski, and M. Migliaccio. 2009. "The Two-Scale BPM Scattering Model for Sea Biogenic Slicks Contrast." IEEE Transactions on Geoscience and Remote Sensing 47 (7): 1949-1956. doi:10.1109/TGRS.2009.2013135.

Pinel, N., C. Bourlier, and I. Sergievskaya. 2014. "Two-Dimensional Radar Backscattering Modeling of Oil Slicks at Sea Based on the Model of Local Balance: Validation of Two Asymptotic Techniques for Thick Films." IEEE Transactions on Geoscience and Remote Sensing 52 (5): 2326-2338. doi:10.1109/TGRS.2013.2259498.

Pinel, N., N. Déchamps, and C. Bourlier. 2008. "Modeling of the Bistatic Electromagnetic Scattering from Sea Surfaces Covered in Oil for Microwave Application." IEEE Transactions on Geoscience and Remote Sensing 46 (2): 385-392. doi:10.1109/TGRS.2007.902412.

Remote Sensing System. 2017. "Remote Sensing System Database." Accessed 4 March 2018. http:// www.remss.com/measurements/wind/

Shivola, A. H. 1989. "Self-Consistency Aspects of Dielectric Mixing Theories." IEEE Transactions on Geoscience and Remote Sensing 27 (4): 403-415. doi:10.1109/36.29560.

Singha, S., T. J. Bellerby, and O. Trieschmann. 2013. "Satellite Oil Spill Detection Using Artificial Neural Networks." IEEE Journal of Selected Topics in Applied Earth Observation and Remote Sensing 6 (6): 2355-2363. doi:10.1109/JSTARS.2013.2251864. 
Skrunes, S., C. Brekke, and T. Eltoft. 2014. "Characterization of Marine Surface Slicks by Radarsat-2 Multipolarization Features." IEEE Transactions on Geoscience and Remote Sensing 52 (9): 5302-5319. doi:10.1109/TGRS.2013.2287916.

Skrunes, S., C. Brekke, T. Eltoft, and V. Kudryavtsev. 2015. "Comparing Near-Coincident C- And XBand SAR Acquisitions of Marine Oil Spills." IEEE Transactions on Geoscience and Remote Sensing 53 (4): 1958-1975. doi:10.1109/TGRS.2014.2351417.

Skrunes, S., C. Brekke, C. E. Jones, and B. Holt. 2016. "A Multisensor Comparison of Experimental Oil Spills in Polarimetric SAR for High Wind Conditions." IEEE Journal of Selected Topics in Applied Earth Observation and Remote Sensing 9 (11): 4948-4961. doi:10.1109/JSTARS.2016.2565063.

Solberg, A. H. S. 2012. "Remote Sensing of Ocean Oil-Spill Pollution." Proceedings of the IEEE 100 (10): 2931-2945. doi:10.1109/JPROC.2012.2196250.

Solberg, A. H. S., C. Brekke, and P. O. Husoy. 2007. "Oil Spill Detection in Radarsat and Envisat SAR Images." IEEE Transactions on Geoscience and Remote Sensing 45 (3): 746-755. doi:10.1109/ TGRS.2006.887019.

Solberg, A. H. S., G. Storvik, R. Solberg, and E. Volden. 1999. "Automatic Detection of Oil Spills in ERS SAR Images." IEEE Transactions on Geoscience and Remote Sensing 37 (4): 1916-1924. doi:10.1109/36.774704.

Suresh, G., C. Melsheimer, J. -. H. Korber, and G. Bohrmann. 2015. "Automatic Estimation of Oil Seep Locations in Synthetic Aperture Radar Images." IEEE Transactions on Geoscience and Remote Sensing 53 (8): 4218-4230. doi:10.1109/TGRS.2015.2393375.

Valentine, D. L., G. B. Fisher, S. C. Bagby, R. K. Nelson, C. M. Reddy, S. P. Sylva, and M. A. Woo. 2014. "Fallout Plume of Submerged Oil from Deepwater Horizon." Proceedings of the National Academy of Sciences of the United States of America 111 (45): 15906-15911. doi:10.1073/ pnas.1414873111.

Velotto, D., M. Migliaccio, F. Nunziata, and S. Lehner. 2011. “Dual-Polarized TerraSAR-X Data for Oil Spill Observation." IEEE Transactions on Geoscience and Remote Sensing 49 (12): 4751-4762. doi:10.1109/TGRS.2011.2162960.

Vilcaez, J., L. Li, and S. S. Hubbard. 2013. "A New Model for the Biodegradation Kinetics of Oil Droplets: Application to the Deepwater Horizon Oil Spill in the Gulf of Mexico." Geochemical Transactions 14 (1): 4-14. doi:10.1186/1467-4866-14-4.

Voronovich, A. G. 1985. "Small Slope Approximation in Wave Scattering by Rough Surfaces." Soviet Physics Journal ETP 62 (1): 65-70. doi:10.1088/0959-7174/4/3/008.

Wismann, V., M. Gade, W. Alpers, and H. Huhnerfuss. 1998. "Radar Signatures of Marine Mineral Oil Spills Measured by an Airborne Multi-Frequency Radar." International Journal of Remote Sensing 19 (18): 3607-3623. doi:10.1080/014311698213849.

Woods Hole Oceanographic Institution (WHOI). 2011. Oil in the Ocean: Natural Oil Seeps. Athens, Greece. Accessed 22 February 2018. http://www.whoi.edu/oil/natural-oil-seeps.

Xu, L., M. J. Shafiee, A. Wong, and D. A. Clausi. 2016. "Fully Connected Continuous Conditional Random Field with Stochastic Cliques for Dark-Spot Detection in SAR Imagery." IEEE Journal of Selected Topics in Applied Earth Observation and Remote Sensing 9 (7): 2882-2890. doi:10.1109/ JSTARS.2016.2531985. 